\title{
Regeneration Strategy on Historic Urban Landscape (HUL) Based on Case Study
}

\author{
Lian Jingsen*, Liao Muyun \\ School of Architecture, Central Academy of Fine Arts, Beijing, Republic of China \\ Email address: \\ 1214450097@qq.com (Lian Jingsen) \\ ${ }^{*}$ Corresponding author
}

\section{To cite this article:}

Lian Jingsen, Liao Muyun. Regeneration Strategy on Historic Urban Landscape (HUL) Based on Case Study. International Journal of Architecture, Arts and Applications. Vol. 7, No. 2, 2021, pp. 33-44. doi: 10.11648/j.ijaaa.20210702.12

Received: April 26, 2021; Accepted: May 19, 2021; Published: May 24, 2021

\begin{abstract}
The background of this thesis is that Italy's large cultural heritage overlaps extensively with urban constructions. Research and practice on this issue have achieved successful results and examples worth learning from. This study contains a systematic review of the development process of Italian urban cultural heritage conservation, and a brief description of the historical urban landscape (HUL) concept and method, and the notion of "regeneration" under the premise of inserting "dynamic", "activation" and "sustainability" in heritage conservation. The research method of this paper is to analyze several successful cases of Italian cultural heritage regeneration, three strategies of Italian landscape heritage regeneration under the HUL theory were summarized: "landscape" layering of urban and historic elements under the strategy of connecting sections; "activating" the historical landscapes using heritage as the catalyst; driving the sustainable use of historic urban landscapes with the power of community. In addition, Facing many problems of Chinese cultural heritage, three important points are provided for the development of HUL regeneration strategies dealing with urban sprawl in China including focusing on the historical and cultural "layering", establishing a multi-criteria assessment system about heritage and promoting public participation as a long term driving force of urban renovation.
\end{abstract}

Keywords: Urban Historical Landscape (HUL), Italy, Regeneration Strategy, Case Analysis, Cultural Heritage

\section{Background}

\subsection{The Development of Historic Urban Landscape (HUL) in Italy}

As an ancient civilization, Italy ranks in the forefront of the world in terms of the scale and quantity of cultural heritages. National Association of Historic and Artistic Centers (ANCSA) estimates that there are more than 20,000 historic settlements in Italy [1], including urban historic areas, historic villages and towns scattered in the mountains and suburbs. According to the official data of the Italian cultural heritage online platform (Vincoli in Rete), as of January 2021, there are 206,840 immovable properties under the protection of Codice dei Beni Culturali e del Paesaggio (Cultural Heritage and Landscape Code) [2]. Due to the strong continuity of Italian history and culture, these townscapes are shaped by "historic archetypes" of different eras, presenting an overlapping of highly recognizable cultural layers. After a hundred years of exploration and experimentation on the protection of historical towns, these densely scattered immovable heritages, planar historic settlements and modern cities are blended in an organic way.

The transformation, development and improvement of Italy's historic urban landscape approach are inseparable from the shift in urban planning ideas, which has gone through three stages: 1) "dialectically differentiate the exist and the new" in the early stage of urbanization; 2) "critically adaptive reuse" in the middle stage of urbanization; 3) "conserve and integrate" in the later stage of urbanization.

1) The urbanization in Italy began from the middle of the 19th century under the influence of the second industrial revolution. It was hard for the emerging industries to thrive in the old urban fabric, worsening the "city disease". In his book New Design in Old Cities, Gustavo Giovannoni proposed to differentiate the old and the new dialectically when dealing with the conflict between old cities and modern architectures [3]. At that 
time, however, the method was limited to repairing the historic part of cities in a simple and modernized way.

2) After World War II, due to the eagerness to restore the cities destroyed by the war, the blind pursuit of an economic-oriented urban reconstruction plan led to serious damage to the local historic landscape and traditional buildings in Italy. At the same time, rising national consciousness led domestic architects, planners and heritage conservation workers to focus on the conservation and restoration of cultural heritages. Bearing the idea of "critical" urban renewal, the Charter of Gubbio (1960) was created, putting forward targeted and adaptable guidance in the face of specific issues at different levels concerning the historic urban landscape.

3) Since the $1980 \mathrm{~s}$, in the globalization and post-industrial era, Italy has faced multiple challenges rising from urban transformation and the decline of historic areas. Thus the regeneration of historic landscapes was emphasized upon the accumulation of traditional practices in conservation and restoration. This spurred Italian conservers to think outside of the single-disciplinary framework, re-examine the social and humanistic connotations of urban tangible heritages in the multiple contexts of urban development, and establish a comprehensive strategy for historic urban landscape regeneration that integrates legislation, economics, policy making, and scientific research.

\subsection{Historic Urban Landscape and the HUL Approach}

As "dynamic", "activation" and "sustainability" became the keywords acknowledged by the field of heritage conservation, the conceptual content of HUL has undergone a transformation from theoretical research to a summary of practical approach [4], which mainly consists of two parts: 1) as the object being conserved; 2) as the conservation approach.

1) The expanding concept of historic urban landscape as the object being protected can be traced back to the Recommendation concerning the Safeguarding and Contemporary Role of Historic Areas made in 1976. The definitions of "historic areas" includes not only natural spaces and building clusters, but also the dynamic succession of artificial environment. The Vienna Memorandum on "World Heritage and Contemporary Architecture - Managing the Historic Urban Landscape" released in 2005 addressed the importance of the emotional connection between human beings and the natural environment in cultural-historic context. The objective has shifted from heritage to cultural landscape.

2) "Landscape" has a methodological meaning in human geography, so historic urban landscape is regard as a working method that is used to explore the continuous and dynamic interaction mechanism among a variety of tangible and intangible elements in the historic layers of urban and natural environment. In the "Report on the Incorporating Historic Urban Landscapes approach in the Operational Guidelines for the Implementation of the World Heritage Convention" issued in 2001, the Historic urban landscape (HUL), for the first time, appeared as a methodology in the summary of the international conference. Subsequently, the "UNESCO Recommendation on the Historic Urban Landscape" (hereinafter referred to as the "Recommendation") promulgated in 2011 further clarified that HUL approach is a tool and a methodology in the process of continuous urban evolvement [5], to provide corresponding strategies for the rational distribution of historic resources, natural resources and human resources. Various heritage stakeholders introduced to the development of HUL multi-source information platform, to integrate environmental elements in the existing space, and to establish of a balance between the collective memory of different eras and scenes under different geographical backgrounds. [6].

\subsection{Notion of HUL Regeneration}

In a narrow sense, if heritage conservation approaches are scaled according to the degree of human intervention and damage, it is generally believed that "regeneration" lies between "restoration" and "reconstruction" [7]. In a broad sense, "regeneration" is a relatively late stage in the cultural heritage conservation workflow, which refers to the reuse of the original material remains after the heritage is protected and recovered with scientific and rigorous methods, including the transformation of physical space and the endowment of new functional attributes, so as to realize the adaptation of the heritage to modern urban life and the continuation of the historical context [8].

From the perspective of HUL, the focal point of regeneration is the renewal of urban landscape heritage, the re-examination and upgrading of the historic layering, and build an effective heritage value management framework through a series of means such as space design, structural transformation, business implantation, management and operation, to "activate" the urban area where the historical landscape is located. More than being "resurrection from the dead", "regeneration" endows urban landscape heritage conservation with foresight, stability and sustainability through real-time collection of historical information, management analysis, and dynamic monitoring.

The six steps of the HUL methodology [9] reflect that the regeneration of urban landscape heritage is not only a result of protection, recovery and design, but more importantly, as a process of heritage conservation [10]. In this process, more urban individuals with different identities and more diverse discipline theories and practices are incorporated through the perspective of "landscape", in order to cater to both "public interest" and "private interest" [11], and find the crossing point between "expert Acknowledge" and "local Acknowledge" [12].

Different from the linear progression that traditional urban heritage conservation is gradually following, the regenerative connotation of HUL is embodied in a self-organizing model 
based on a cycle of creativity [13]: After fully exploring multiple values of cultural heritage, a network platform is build through information integration technology to provide different stakeholders customized heritage information services and meet their needs. The commercial, social and environmental values created by different stakeholders based on their respective urban visions in turn fund the conservation of urban landscape heritage [14], forming a virtuous self-circulation of HUL.

\section{Analysis of the HUL Regeneration Strategy}

In recent years, Italy has made many attempts to "regenerate" HUL. The objects of practice include ancient city walls, ancient villages, monasteries, churches, historic gardens, archaeological sites and other different types of cultural heritages. The core idea of the "regeneration" strategy is concentrated in three aspects: 1) connecting social constructions of different cultural layers based on the landscape vision; 2) exerting the catalytic effect of the heritages in spatial dimension, to achieve the regeneration goal of "breaking the surface with points"; 3) activate the inherent driving force of community in heritage regeneration to achieve sustainability.

\subsection{Connect Sections - Overlapping of "Landscapes" in Historic Layers}

Urban areas in Italy are known for strong historical continuity, and are often regarded as "collections of collective consciousness in multiple eras" [15]. Italian urban development is a dynamic evolutionary process revolving around static heritage. The "regeneration" in the process of "landscape" layering is a comprehensive process of the layering of both abstract values and physical spaces [16]. When dealing with the "sections" of urban history, Italians not only reuse the aesthetic value and historical value, but also pay attention to the recording and analysis of the natural environment and social factors that influence the evolution of HUL, such as the source of consciousness of the cultural layer, major historical events, and natural disasters, thus the scientific, ecological, and social value of the urban fabric, historic streets or important node buildings are transformed and regenerated precisely.

The Sassi of Matera was included in the UNESCO World Heritage List in 1993. From the perspective of HUL's historic layering, the landscape heritage of this historic part of town has undergone an evolutionary mode of "decay-juxtaposition-regeneration". This process reflects the advantages of the HUL approach in identifying multiple values of the heritage through the expanding notion of "landscape". Sassi was built on the rock cliff, and the tradition of living in cave-like houses can be traced back to 7000 years ago [17]. Before World War II, most of the residents still lived in stone houses built on stone caves. Italy's post-war economy was booming, but due to high humidity and poor lighting, the original buildings of the ancient town were infected with flu, and became a key factor hindering the economic development of the area. Following the advice of experts in different fields, the indigenous residents relocated to the surrounding newly established towns. For the first time in thousands of years, the historical and cultural layers of the ancient town have shown obvious signs of "decay", and the once bustling traditional settlements have become vacant.

After the global expansion of modernism in the 1970s and 1980 s, Italian architects turned their attention to the revival of their own regional culture. With the support of the government, they proposed the regeneration strategy of "repair for rent", which attracted a large number of intellectuals, the upper middle class, artists, and designers. They used limited intervention in the architecture and environment in accordance with government standards. However, from the perspective of "landscape", the social network formed by the new residents and the original settlement space were heterogeneously embedded, meaning it has not blended in with the overall style, urban fabric, and surrounding communities of the ancient town. An obvious "juxtaposition" of cultural layers was created.

Since it was listed as a World Heritage in 1993, the government has systematically managed the value of local historic landscape with movie and television promotion, economic means, legal protection, administrative management, and public participation. The relationship between spatial and cultural connections made by the original settlements was coordinated. New residents were encouraged to establish multi-field cooperation between their cultural layer and the original community layer, including culture, ecology, commerce, and multimedia, to narrow the gap between the old and the new. In recent years, a variety of spatial analysis techniques have been applied to quantify, monitor, compare and analyze the environmental and social factors of this ancient town. For instance, through the use of "Map Algebra" and "Kernel Density Estimation" in GIS environment, the decay indexes (DI) of street facades material were processed to calculate the degree of damage to the heritage caused by different climatic factors, which provided the basis for future protection plans and countermeasures [18] (Figures 1-2). A "smart historic community" as a "symbiotic ecosystem", "citizen identity recognition system" and "information service platform" (Table 1) has been built via urban residential environment modeling, spatial syntax and communication technologies, as an attempt to conduct multidisciplinary research on the relationship among the layers of landscape heritage [19]. Through these efforts, Matera was titled "European Capital of Culture" (ECOC) in 2019. Horizontally, the influence of its cultural value has extended to more regions, and vertically, the connecting of historic sections has been further deepened. The modernization transformation and interpretation of the prehistoric cave dwelling civilization settlements have become more developed and systematic. 


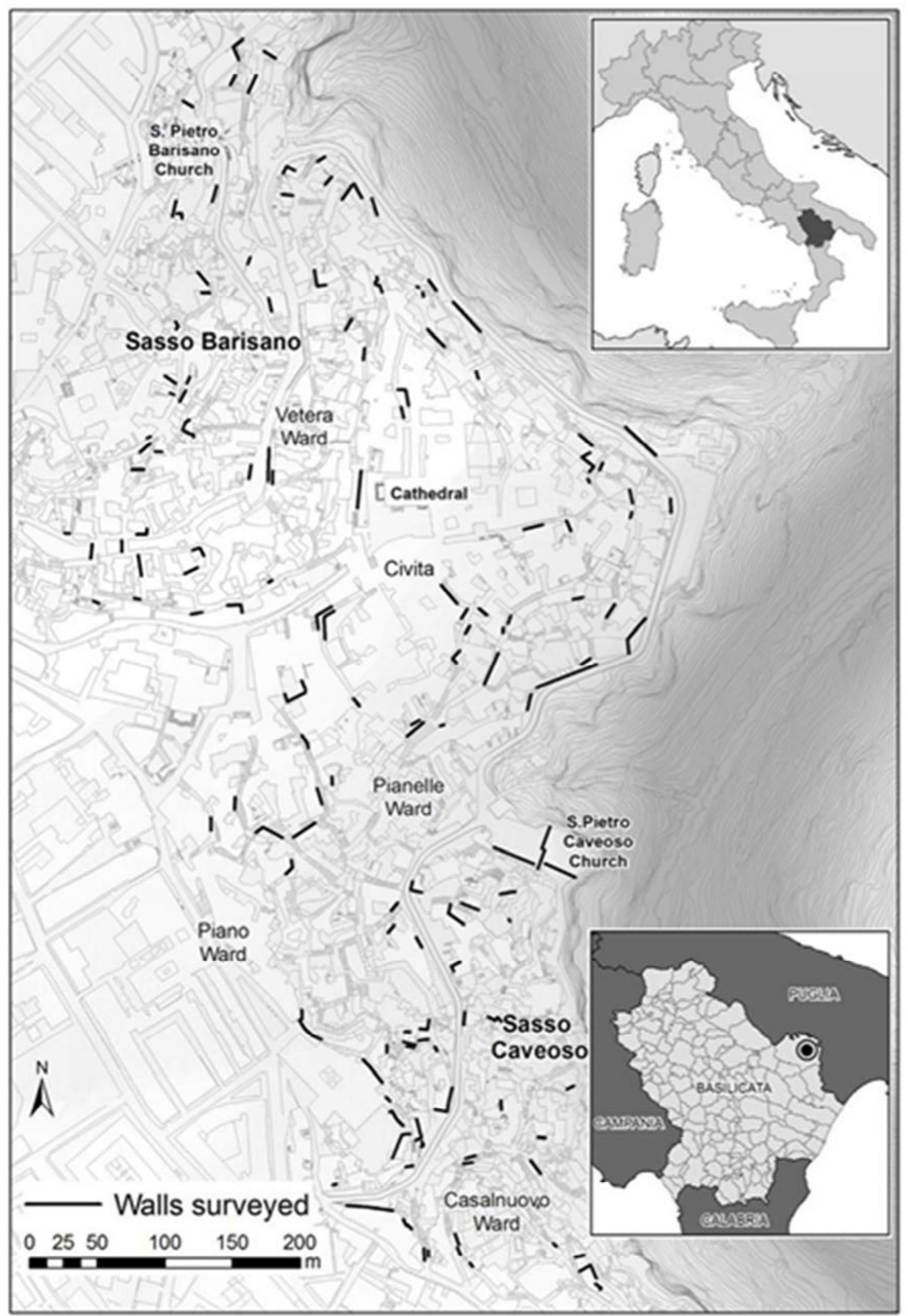

Figure 1. Distribution of historic buildings and facades in the Sassi of Matera. Form, The conservation state of the Sassi of Matera site (Southern Italy) and its correlation with the environmental conditions analysed through spatial analysis techniques [18]. 


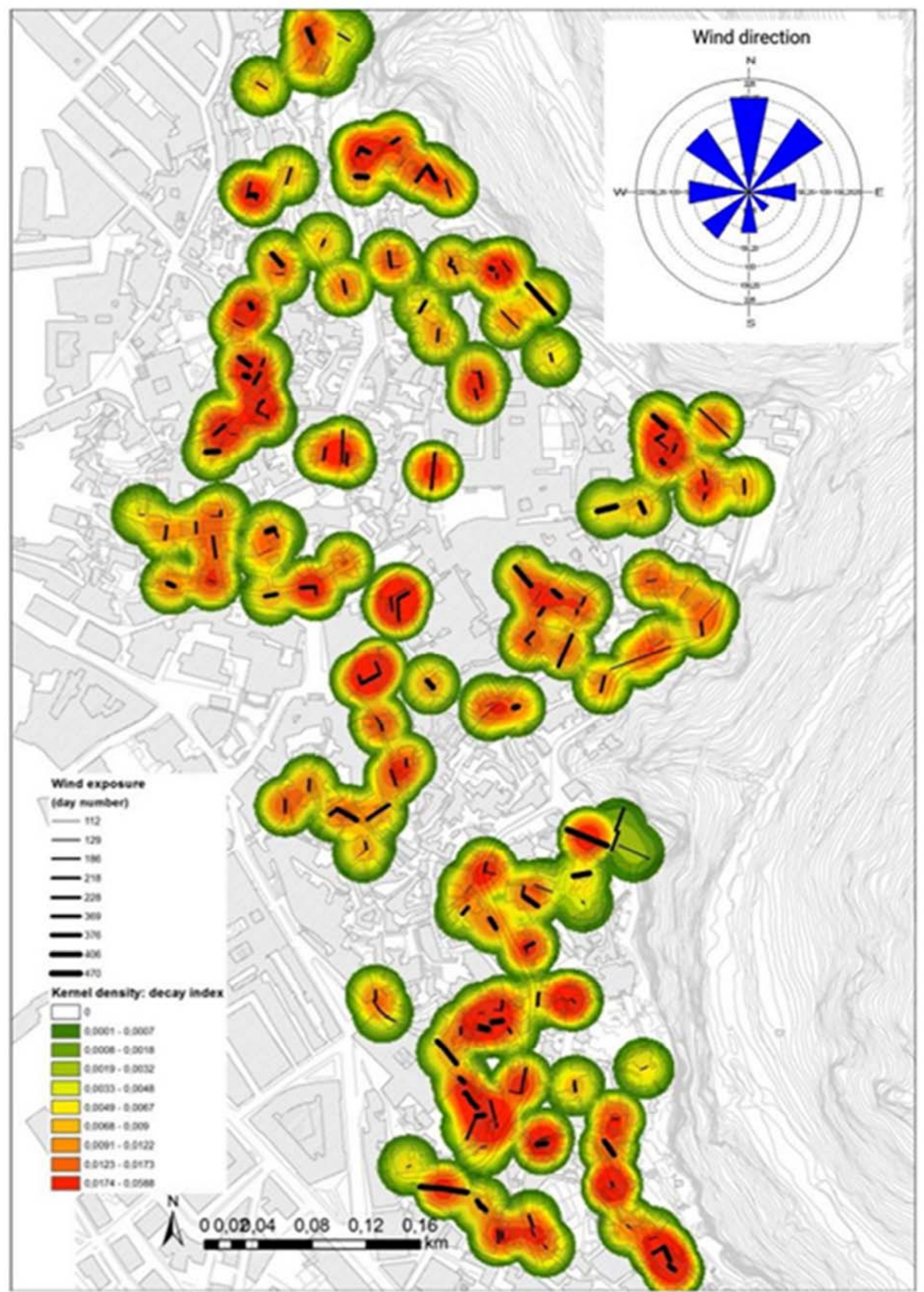

Figure 2. Decay index (DI) analysis of street facades using Kernel Density Estimation Form, The conservation state of the Sassi of Matera site (Southern Italy) and its correlation with the environmental conditions analysed through spatial analysis techniques [18]. 
Table 1. Construction model for "smart historic community".

\begin{tabular}{|c|c|c|c|}
\hline \multirow{2}{*}{ Project } & \multicolumn{2}{|l|}{ content } & \multirow{2}{*}{ Landscape method of historic } \\
\hline & Service objective & Technique/strategy & \\
\hline $\begin{array}{l}\text { CLARA-Cloud } \\
\text { platform for } \\
\text { Landslide Risk } \\
\text { Assessment }\end{array}$ & $\begin{array}{l}\text { Water supply and drainage pipe } \\
\text { network control, groundwater level } \\
\text { monitoring, surface water pollution } \\
\text { monitoring, and natural disaster } \\
\text { prediction system at ancient heritage } \\
\text { sites } \\
\text { The construction of a smart network } \\
\text { for government administration }\end{array}$ & $\begin{array}{l}\text { Network management of } \\
\text { micro sensors } \\
\text { 3D virtualization } \\
\text { Development and application } \\
\text { of various software based on } \\
\text { Web2.0 } \\
\text { 4D tomography }\end{array}$ & $\begin{array}{l}\text { Historic data of the urban and suburb heritage are collected, } \\
\text { stored, and managed using modern digital landscape } \\
\text { technology. Heritage's values are translated, disseminated, } \\
\text { and used for educational purpose through modern display } \\
\text { technologies, for building an information bridge between the } \\
\text { modern city and the heritage site. }\end{array}$ \\
\hline Smart Basilicata & $\begin{array}{l}\text { Smart natural resources (overcome the } \\
\text { limitations of current environmental } \\
\text { monitoring system) } \\
\text { Smart energy (support the } \\
\text { development of energy zones in } \\
\text { agricultural valleys) } \\
\text { Smart mobility (improve the safeness } \\
\text { of traffic infrastructure) } \\
\text { Smart culture and tourism (build } \\
\text { real-time 3D model to improve } \\
\text { accessibility) } \\
\text { Smart participation (offer advanced } \\
\text { planning methods to decision makers } \\
\text { and promote participation using } \\
\text { communication techniques) }\end{array}$ & $\begin{array}{l}\text { Integration of supporting } \\
\text { technologies } \\
\text { A cloud computing platform } \\
\text { for acquiring and using data } \\
\text { and services } \\
\text { Service-Oriented } \\
\text { Architecture (SOA) } \\
\text { Sensors and advanced micro } \\
\text { sensor networks (including } \\
\text { "Mesh Network") } \\
\text { Earth Observation (EO) } \\
\text { Technologies related to the } \\
\text { Internet of Things (interface } \\
\text { NFC, RFID) }\end{array}$ & $\begin{array}{l}\text { The Smart Basilicata project is based on the background of } \\
\text { participatory planning, in the latest Internet of Things } \\
\text { paradigm, based on modern earth observation technology and } \\
\text { information and communication technology to capture earth } \\
\text { surface environment, society, energy, cultural heritage and } \\
\text { other landscape elements. } \\
\text { It aims to help the modern urban part and the historic center } \\
\text { part to plan the future more scientifically, make the city more } \\
\text { resilient and sustainable, and make Basilicata a "smart } \\
\text { historic community". }\end{array}$ \\
\hline unMonastery & $\begin{array}{l}\text { Social issues in cities } \\
\text { Non-religious groups }\end{array}$ & $\begin{array}{l}\text { Open financing } \\
\text { Open street map compilation } \\
\text { sustainable business } \\
\text { development plan } \\
\text { Open partnership } \\
\text { Open Space Initiative }\end{array}$ & $\begin{array}{l}\text { UnMonastery is inspired by monastery life in the 10th } \\
\text { century. It emphasizes the humanistic and spiritual } \\
\text { connotation of a community's historic landscape. The core of } \\
\text { its concept is to recover the "clinic function" of the traditional } \\
\text { monastery to achieve "spiritual healing" in the future society. } \\
\text { This place-based social innovation aims to develop a new } \\
\text { type of social space similar to co-living and co-working } \\
\text { spaces, and by leveraging the appeal of religious heritage to } \\
\text { the city, and integrating different urban stakeholders with } \\
\text { dedication into the community to solve the wasteful space } \\
\text {, unemployment and the depletion of social services. } \\
\text { The purpose of the project is to establish a "spiritual } \\
\text { connection" between traditional historic heritage and modern } \\
\text { living groups. }\end{array}$ \\
\hline
\end{tabular}

\subsection{Heritage Catalyst - "Activating” the Historic Landscape}

Since the beginning of the 21 st century, excessive commercial development led by globalization and informatization has once again impacted the integrity and authenticity of HUL in Italy. In recent years, the catalytic effect of historic landscapes is being leveraged as a result of Italy's regeneration strategy on the fragmented and scattered HUL in the modern context. The extraction of landscape elements and the intervention of design carriers were applied to complete the transformation and promotion of heritage's values, so as to achieve the regeneration goal of "breaking the surface with points" at the urban renewal level.

Minerva's Garden (Giardino della Minerva) is located in the heart of the old town of Salerno (Figures 3-4), laying on "Bonadies Hill". In addition to the unique visual resources and tourism value brought by the typical Italian style "terrace garden", more than 350 ancient and precious botanical species provide medical, scientific and educational value.

The garden was built in the $1420 \mathrm{~s}$ as a medicinal botanical garden for the local medical school [20], and the post World War II restoration was completed in September 2000 with the support of the European Regional Development Fund (ERDF) [21]. The botanical garden was protected by tall walls in a "freezing" and "isolated" way. The purpose was to keep the internal environment from being disturbed, because the medieval pastoral surroundings has been replaced by busy modern infrastructure.

"Circular Models Leveraging Investments in Cultural Heritage Adaptive Use" (CLIC) project was launched in July 2019 [22] (Figure 4) to replace this simple protection mode. Aiming to explore the historic landscape elements of cultural heritage based on the principles of circular economy, the CLIC project unites stakeholders in various fields, such as legislation, technology, government, business model, and civil organization, through a multidisciplinary and systematic approach to exert HUL's catalyst effects on society, environment, economics and culture, to achieve flexibility, inclusiveness and sustainability. CLIC project re-examined the unique medical, ecological, historical, cultural and artistic value, and enabled Minerva's Garden to become the symbol of Salerno as the "city of health" (città della salute), and a nominee of the "most beautiful garden in Italy" (Ill parcopiùbello d'Italia). 


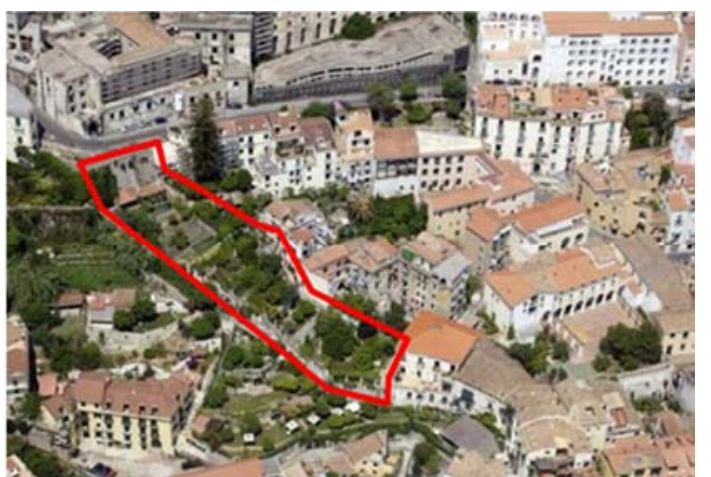

Figure 3. Giardino della Minerva aerial view , From https://per-andare-dove-dobbiamo andare.webnode.it/products/salerno/.

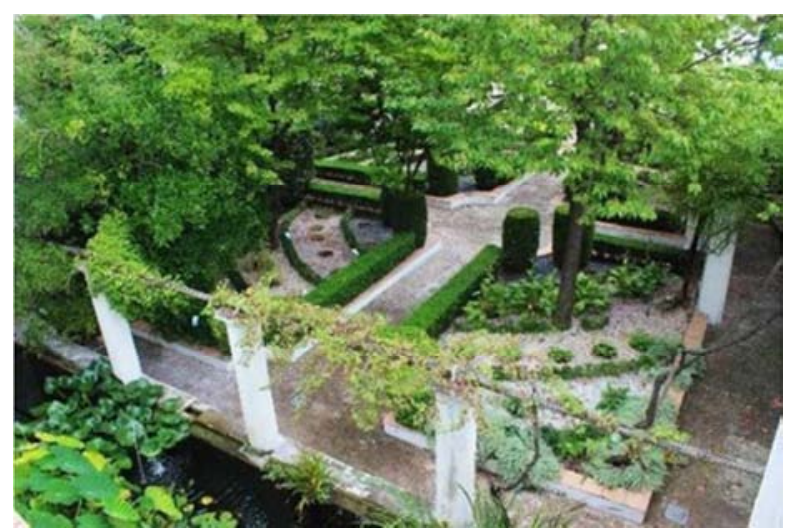

Figure 4. Giardino della Minerva Ground Floor Plaza, From : https://www.diarioviaggi.eu/i-giardini-della-minerva-il-cuore-verde-di-saler no/andare.webnode.it/products/salerno/.

THE FUNCTIONAL REUSE: FROM COST TOWARDS INVESTMENT

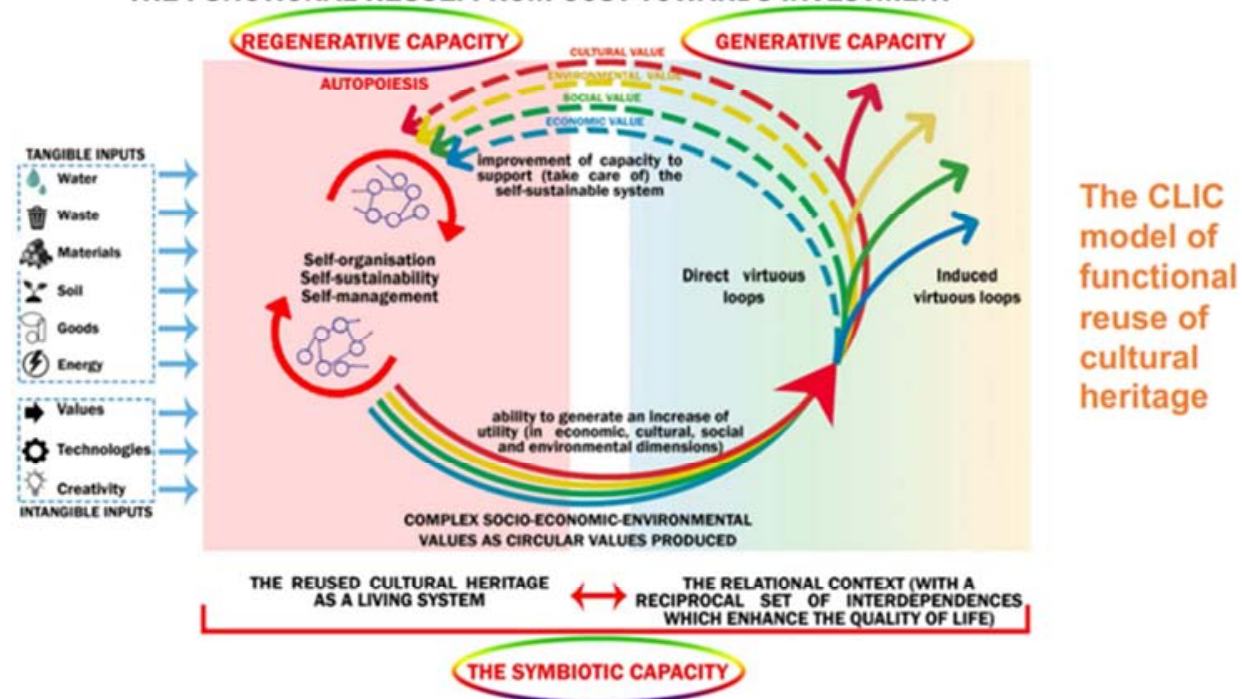

Figure 5. CLIC cultural heritage regeneration cycle model. From CLIC Union. CIRCULAR MODELS LEVERAGING INVESTMENTS IN CULTURAL HERITAGE ADAPTIVE REUSE [19].

The integration and efficient output of the garden's cultural resources has reduced operating costs, increased the willingness to invest, and attracted more corporate and private donations. The fund is managed by a non-profit organization, Foundation of the Schola Medical Salernitana, for organizing social activities on the theme of garden history, botany, medical care, and further enhancing the heritage value of Minerva's Garden as the driving force of urban and regional. For example, a lighting event named "Lumina Minervae" took place in the garden (Figures 5-7), which was created by lighting designers, installation artists, medical consultants, landscape designers and experts from various fields. Mixed media incorporating light, image, film, and sound were used to reveal the mysterious and religious historical stories behind the Minerva's Garden [23]. The application of various exhibition techniques allowed the landscape heritage to evolve from a "memorial" to a catalyst that activates the development of regional culture.

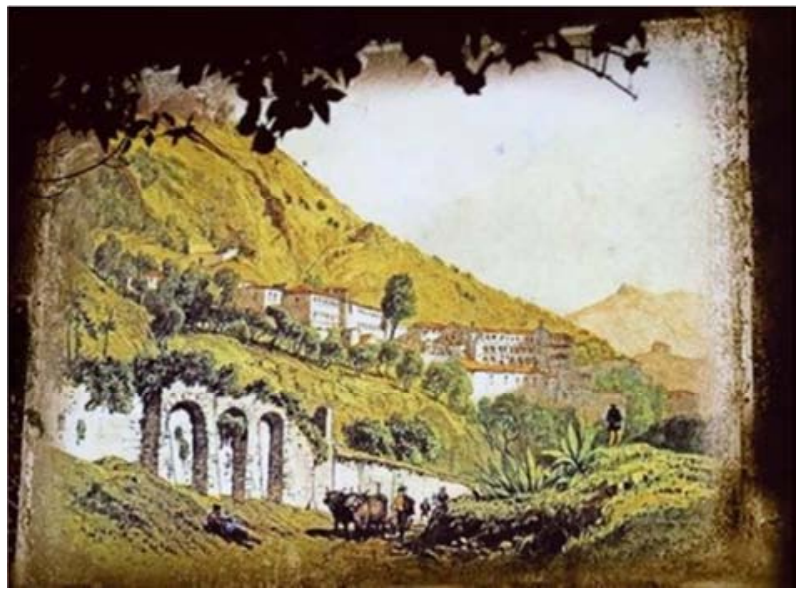

Figure 6. Projection of the garden in "Lumina Minervae" Botanical Garden Theme Lighting Exhibition. From: https://www.lucidartista.it/lumina-minervae-installazioni-luminose-nel-giard ino-della-minerva.html. 


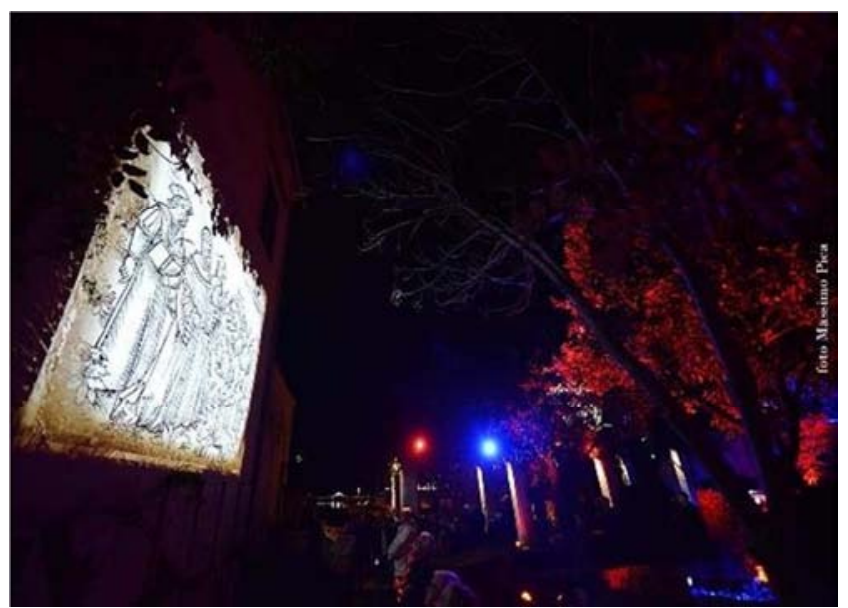

Figure 7. Projection of the medicinal plants in "Lumina Minervae" Botanical Garden Theme Lighting. From: https://www.lucidartista.it/lumina-minervae-installazioni-luminose-nel-giard ino-della-minerva.html.

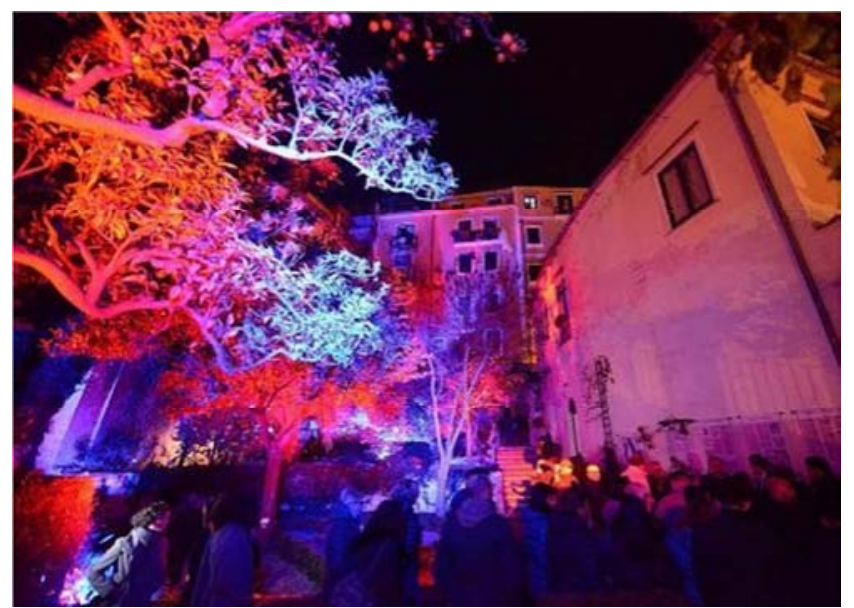

Figure 8. "Lumina Minervae" Botanical Garden Theme Lighting. From: https://www.lucidartista.it/lumina-minervae-installazioni-luminose-nel-giard ino-della-minerva.html.

\subsection{Driving Force of Urban Communities - Sustainability of Historic Landscapes}

Urban landscape heritage is the epitome of daily life of the past. As a unified body of social connections, "Community"'s sufficient cultural, ecological, and social capacity can incorporate HUL into a more comprehensive and systematic heritage conservation system, with community as the fundamental driving force providing sustainable external conditions for HUL regeneration. In Italy, community is regard as a driving force of the regeneration of HUL in terms of public participation. The national government has issued an "adopter policy" to provide macro-level support in the transfer of land use rights and heritage development and management rights. More importantly, local communities engage residents through encouraging artistic intervention, talent training, cultural promotion, and private business, and enhance the public's awareness of participating in urban heritage conservation [24], thereby promote the implementation of the medium and long-term goals of HUL regeneration.
Castello dell' Acciaiolo was an old castle built in the Middle Ages. It has undergone renovation, expansion, abandonment, destruction and other changes under the influences of Renaissance, the Baroque, the Enlightenment and World War II. It was acquired by the Italian government as a public property in 1998 [25]. Thanks to the joint effort of the University of Florence, local government, handicraftsmen, designers and Gucci, the restoration was completed in 2010, and the property is used as a center for leather crafts exchange, exhibition, training and public green space of local communities [26] (Figures 8-13).

From the perspective of local communities, the castle has two important identities: 1) as a center for handicraft exchange; 2) as a "community garden" for public recreation. 1) The town of Scandicci, where the project is located, has a long history of leather production, so there are many craftsmen who make products for international luxury brands. Albeit rich experience and superb skills, their business were limited by the operating mode of small companies, scattered layout, improper management, lack of financial support, and a collaborative and innovative working environment for industry exchanges to create more value [27]. Located in the center of the city, Castello dell'Acciaiolo provides easy accessibility for many handicraft workshops. Small business workers can discuss and communicate in this property. The historical, cultural and artistic value of the castle and can be transformed to brand advantage that attracts investment and donations. 2) The town of Scandicci basically maintains the medieval urban fabric, lacking a intact, centralized public green space like this castle manor. Before the government acquired the property and closed it down in 1998, it has always been a community garden loved by the residents, which called it "oasis" (oasi). Locals often came here for recreation, and it was an outdoor playground for children. Also, it was a habitat of many small animals and plants.

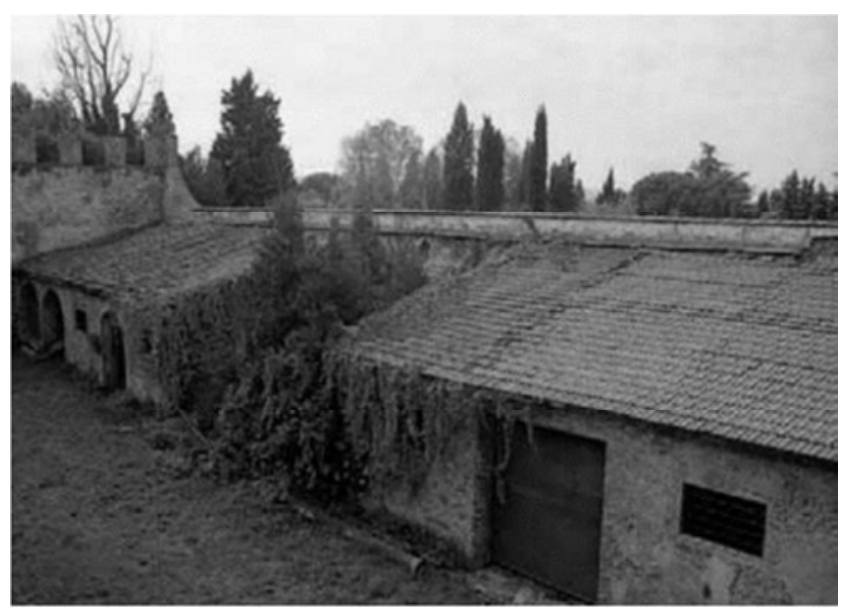

Figure 9. Garden entrance before restoration and regeneration. From Il castello dell' Acciaiolo a Scandicci:un complesso monumentale restaurato [26]. 


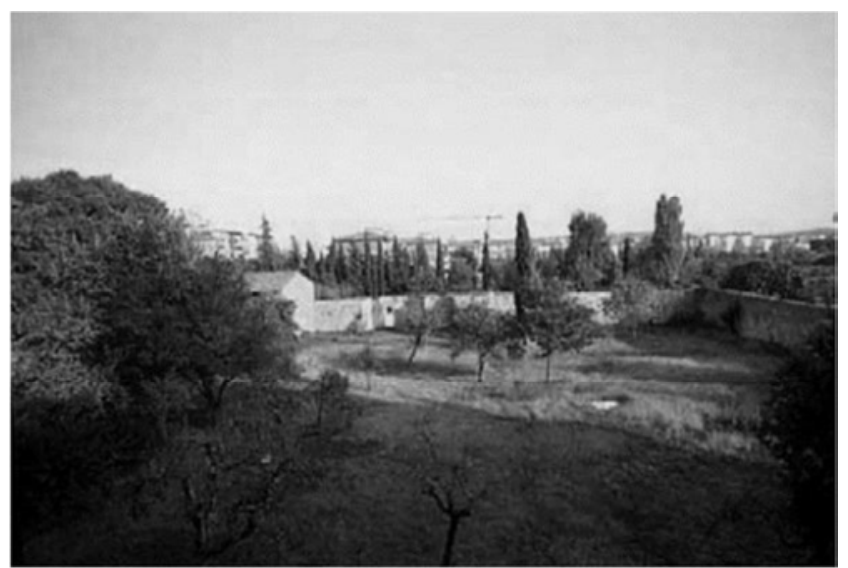

Figure 10. Landscape inside the garden before restoration and regeneration From Il castello dell' Acciaiolo a Scandicci:un complesso monumentale restaurato [26].

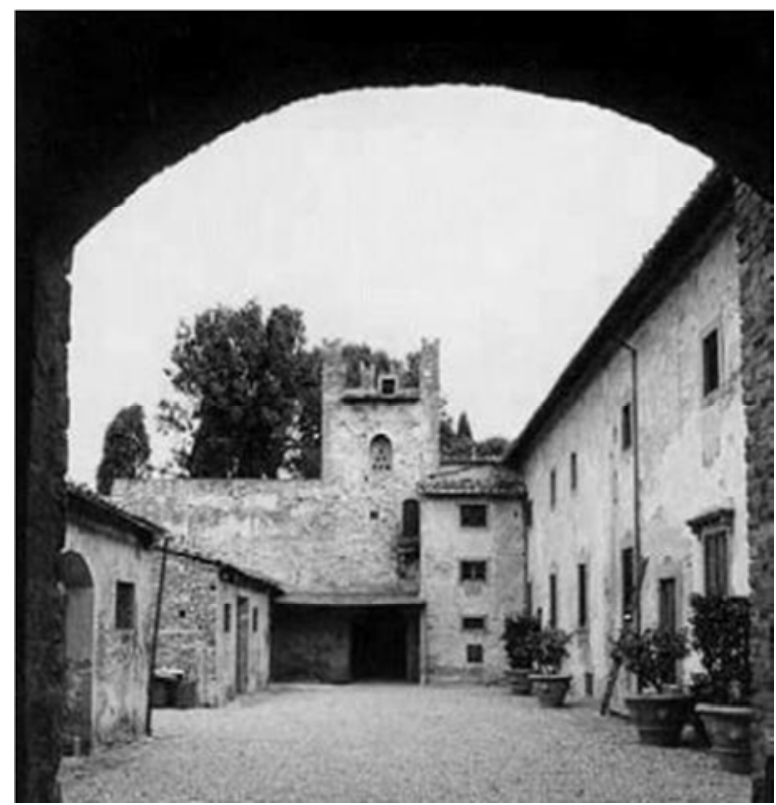

Figure 11. Landscape inside the castle before restoration and regeneration. From Il castello dell'Acciaiolo a Scandicci:un complesso monumentale restaurato [26].

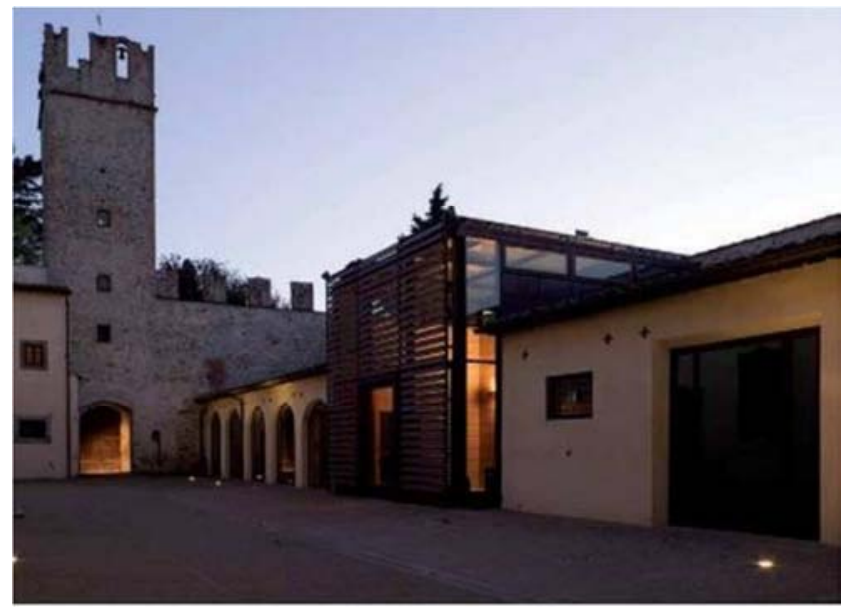

Figure 12. Garden entrance after restoration and regeneration. From Il castello dell'Acciaiolo a Scandicci:un complesso monumentale restaurato [26].

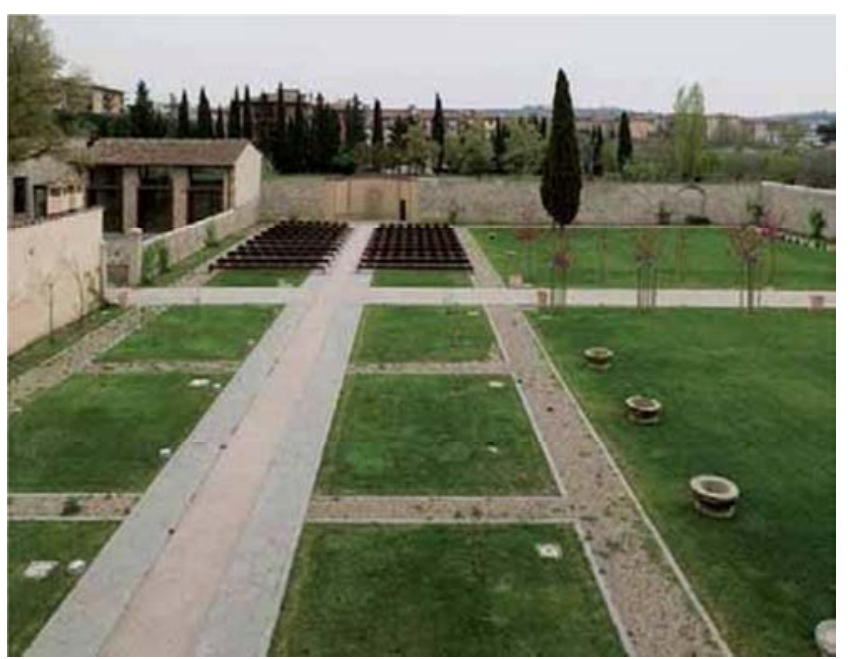

Figure 13. Landscape inside the garden after restoration and regeneration. From Il castello dell'Acciaiolo a Scandicci:un complesso monumentale restaurato [26].

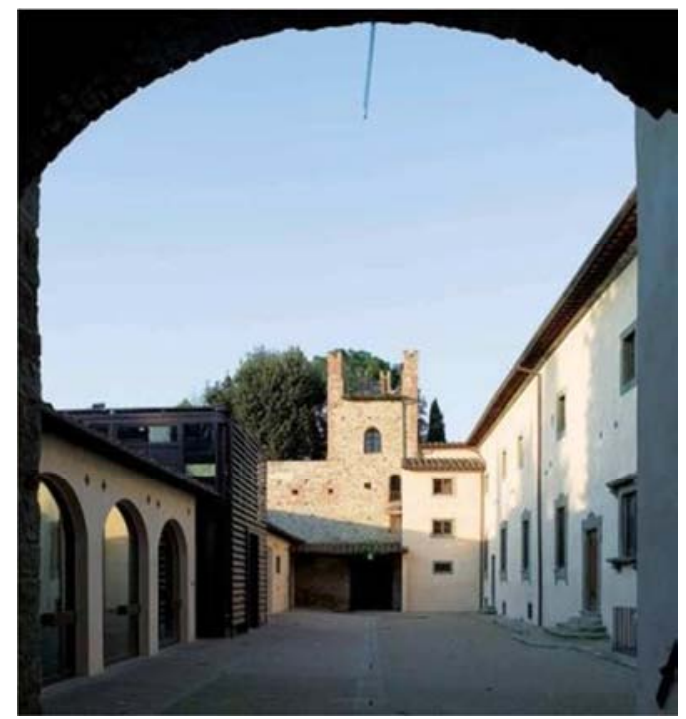

Figure 14. Landscape inside the castle after restoration and regeneration. From Il castello dell'Acciaiolo a Scandicci:un complesso monumentale restaurato [26].

After the Castello dell'Acciaiolo was opened to the public, it was widely recognized by the society. Different social groups gather here to make contributions to the development of the community and the town. Except for the highly professional restoration and conservation practice, community members can participate in landscape planning, function setting, business operation of the cultural heritage through different means including seminar holding, investment and shareholding, and joint management. [28]. The entire restoration and regeneration process of the castle fully embodies the role of community driving forces in the process of transforming cultural values into social values, and provides a sustainable safeguard for the regeneration of HUL.

\section{What China Can Learn from Italy}

China and Italy are both countries with large cultural 
heritage, and their urban history reflects profound cultural accumulation and outstanding continuity. In the process of modern transformation, the development of China's cultural heritage conservation and restoration model, driven by scholars and practitioners in the early development of the discipline, is on the right path suitable for the Chinese characteristics [29]. Nonetheless, the current theoretical research and practical cases on HUL regeneration strategies in China are yet to be supplemented.

\subsection{Carrier of Regeneration - "Layering" Versus "Layer"}

Upsurges in development are pushing the expansion of newly constructed spaces upon the established urban historic structures. An imbalance has been caused by the superposition of urban historic layers driven by competition for land value. Urban sprawl has created negative impacts on the heritage areas, including conflict, encroachment, coverage, replacement. Initiated in 1982, China's historic city protection policy has been implemented for nearly 40 years, but it mostly focus on the conservation of individual historical layers. There are not enough studies and practical cases that explore the organic relationship among different layers through the broad notion of the "landscape approach", and a HUL regeneration operating system based on the correlation of layers has yet to be formed. As an important feature of HUL methodology, the focal points of "layering" are not limited to natural and cultural elements, material and non-material elements at different cultural layers. Learning from the successful cases in Italy, compared with the noun form of "layer", its verb attribute deserves more attention [30], which is especially reflected in the dynamic cumulative results created by the succession of urban landscapes. Therefore, the research object of the HUL regeneration strategy is the relationship among different cultural layers, natural layers, material layers and non-material layers. This "relationship" reflects the law of historical succession, as well as the prediction of future events based on the law.

\subsection{A multi-criteria Assessment System for HUL Regeneration}

Italy's composite and targeted multi-criteria assessment system for different heritage sites is worth learning, because only a sound system can ensure the integrity of characteristics and value recognition, and further realize the transformation of advantages and optimization of regeneration plans. For example, a multi-criteria assessment system based on Analytic Hierarchy Process (AHP) and Geographic Information System (GIS) was developed for villages in south Italy. Values in areas such as ecology, society, art, history, were analyzed to achieve targeted development and utilization plan in the later period [31]. The current domestic assessment criteria for the "materiality" of historical landscapes at the level of object and visible feature identification have already achieved considerable results in terms of literature research, the compilation of regulations and standards, and policy making. However, attempts on the criteria in "emotional memory" of heritage based on the subject level, and emphasizing humanism, are not enough. In addition, the degree of the recognizability of heritage features determines that, the visual features related historical value, cultural value, and artistic value of domestic landscape heritage are often more valued, while the inherent scientific value, social value, and public value of the heritage, the external environmental threat factors and the vulnerability of the heritage are often overlooked. In order to comprehensively and systematically deal with the complex human-land relationship in China, and avoid the one-sidedness of value identification, which would compromise landscape's role as a heritage regeneration tool, it is urgent to promote the developments of an information platform based on multiple heritage values.

\subsection{Promoting Public Participation as a Long Term Driving Force of HUL Regeneration}

Italy's cultural heritage regeneration approach is both "top-down" and "bottom-up" [32]. While executing the right of protection, supervision and ownership of the heritage, the authority endows heritage managerial right to different stakeholders of grassroots organizations and communities. [33]. On one hand, the government, legislatures and other decision-makers can prevent the misunderstanding of heritage conservation due to subjective awareness, thus avoid the formulation of limited or even inaccurate laws and regulations. More importantly, specific social, economic, and environmental issues are fully exposed, efficient and accurate qualitative and quantitative information feedbacks are made, and a sustainable internal cycle of conservation and regeneration is formed through public participation. China's hierarchical territorial management system is conductive to the combination of financial and administrative powers of local governments with the willingness of community members [34]. The key is to enhance the awareness of heritage conservation and regeneration through various methods, so that the government can find a balance point among the management, decentralization and restriction of public participation [35]. This will not only provide community members sufficient and flexible participation means and participation opportunities, but also prevent subjective or unconscious destructive behaviors scientifically and effectively.

The ancient Roman law "Legatum ad patriam" defines the two core notions of cultural heritage, as "public and private goods" and "all daily events within the territory" [36]. This document laid out a broad vision of public participation in cultural heritage. For China, what worth learning is that, through private financing, educational outreach, festivals, and customized activities at heritage sites, the public have the chance to participate in the conservation and recycle of heritage in the development of economy, society, ecology, and environment [37], instead of passively acceptance.

\section{Conclusion}

In the process of modern transformation, Italy's cultural 
heritage conservation strategy has been constantly adjusted and updated, so that it can respond to social issues, conform to economic trends, and coordinate the contradictions between the old and new environments. Currently, the landscape vision is helpful for establishing connections among historic layers, building smart historic communities, establishing multiple cultural value assessment standards, and community participation, in achieving the sustainability of heritage conservation. Italy's HUL regeneration strategy is an important practice in the exploration of "conservation and integration" in the context of urbanization, and drives the development cultural heritage activation and conservation. It has attracted the attention of the Chinese landscape architecture academic and industry.

Large-scale urban informatization is now taking place in China. "Digital cities" are on their way of becoming "smart cities", which brings important opportunities for the regeneration of China's HUL. Under China's unique economic-social-cultural background, the case study on Italian HUL regeneration will shed light on the possibility of China's HUL regeneration from multiple angles. Learning from the successful cases and leveraging its rich cultural heritages and rapid urban development, China is actively investing in the research and practice of domestic HUL regeneration. In general, the new perspectives brought by the Italian HUL regeneration strategy need to be further explored.

\section{References}

[1] Haohao Xu. THE CONSERVATION AND INNOVATION OF ITALIAN URBAN HERITAGE IN THE PO RIVER AREA [D]. South China University of Technology, 2014.

[2] Qian Du, Aihe Liu, Yongkang Cao. The Incentive Mechanism for Public Participation in the Conservation and Utilisation of Cultural Heritage in Italy [J]. Built Heritage, 2019 (04): 51-59.

[3] Yaoyi Feng, Ziye Na. The Envolvement of Conservation Philosophy of Historic Towns in Italy and Implications [J]. Urban Planning Forum, 2016 (01): 99-105.

[4] Wenzhuo Zhang. Landscape Approach for Urban Heritage Conservation-Review and Reflection of the Historic Urban Landscape (HUL) [A]. Chinese society of landscape architecture. Proceedings of 2018 annual meeting of Chinese society of Landscape Architecture [C]. CHSLA, 2018: 8.

[5] Heping Li, Ning Yang. Research on the Management Tools of Historic Urban Landscape - Historic Townscape Characterisation $[\mathrm{J}]$. Chinese Landscape Architecture, 2019, 35 (05): 54-58.

[6] Roders A P, Oers R V. Guidance on heritage impact assessments: Learning from its application on World Heritage site management [J]. Journal of Cultural Heritage Management \& Sustainable Development, 2012, 2 (2): 104-114.

[7] Daixin Dai, Nannan Dong. Protection and Regeneration of Urban Landscape Heritage [M]. Tongji University Press: Shanghai, 2019: 37.

[8] Jianjing Li. Research on the regeneration protection of European World Heritage Cities [D]. Xiamen University, 2014.
[9] UNESCO, WHC. Recommendation on the historic urban landscape. [Z]. Paris: UNESCO, 2011.

[10] Girard, Luigi. Toward a Smart Sustainable Development of Port Cities/Areas: The Role of the "Historic Urban Landscape" Approach [J]. Sustainability (2071-1050), 2013.

[11] Bertacchini E, Bravo G, Marrelli M, et al. Cultural Commons: A New Perspective on the Production and Evolution of Cultures [J]. Chapters, 2012.

[12] Onesti A. HUL Approach, Heritage Community, Living Labs New scenarios for the recovery of built heritage [C]// Quaesti. The 3rd Virtual Multidisciplinary Conference. 2015.

[13] Cominelli F, Greffe X. Intangible Cultural Heritage: Safeguarding for Creativity [J]. City, Culture and Society, 2012, 3: $245-250$.

[14] M. Yang, R. Brumana, M. Previtali. "HERITAGE \& DEVELOPMENT" STRATEGY ON HISTORIC URBAN LANDSCAPE (HUL): THE ADDED VALUE OF MULTI-TEMPORAL HUB APPLICATION [J]. ISPRS International Archives of the Photogrammetry, Remote Sensing and Spatial Information Sciences, 2019, XLII-2/W11.

[15] Cappiello L, Stanzione L. The Regeneration of Historical Centres: A comparative assessment of two Italian cases [J]. People Place and Policy Online, 2020, 14 (3): 216-231.

[16] Yifei Liu. The Anchoring-Layering Theory: for a Better Understanding and Conservation of Historic Urban Landscape [D]. Tsinghua University, 2014.

[17] Chiarella, Domenico, V. Festa, etc. The city of Matera and its 'Sassi'(Italy): an opportunity to broadcast geology in the European Capital of Culture 2019. [J]. Geology Today, 2019, 5: 174-178.

[18] FT. Gizzi, M. Sileo, M. Biscione, etc. The conservation state of the Sassi of Matera site (Southern Italy) and its correlation with the environmental conditions analysed through spatial analysis techniques [J]. Journal of Cultural Heritage, 2016, 17: 61-74.

[19] Cardinale, Tiziana, Laura Pavia, etc. The city of Matera and the Sassi: smart places with a Dantean attraction. [C]. REAL CORP 2014-PLAN IT SMART! Clever Solutions for Smart Cities. Proceedings of 19th International Conference on Urban Planning, Regional Development and Information Society. Austria: CORP-Competence Center of Urban and Regional Planning, 2014. 665-674.

[20] Auletta, Enrico, Luciano Mauro. Il giardino della Minerva: il restauro dell'orto botanico di Salerno [J]. Architettura del paesaggio, 2000, 5: 50-54.

[21] LUCIANO MAURO. Giardino della Minerva - Leaflet $[\mathrm{EB} / \mathrm{OL}]$. https://www.clicproject.eu/wp-content/uploads/2019/07/giardi no-della-minerva-flyer.pdf, 2019-7-15.

[22] CLIC Union. CIRCULAR MODELS LEVERAGING INVESTMENTS IN CULTURAL HERITAGE ADAPTIVE REUSE [R]. Italy: Municipality of Salerno, CNR IRISS, 2019.

[23] Giardino della Minerva. LUCI D'ARTISTA DI SALERNO: Lumina Minervae [EB/OL]. http://www.giardinodellaminerva.it/news/122-luci-d\%E2\%80 \%99artista-di-salerno-lumina-minervae.html, 2017-11-11. 
[24] Labadi S, Gould PG. Sustainable Development: Heritage, Community, Economics. [C]. Global heritage: A reader. USA: Wiley-Blackwell, 2015. 196.

[25] Daniela Lamberini. Le fasi storico-costruttive del Castello dell'Acciaiolo: da castelletto di pianura a villa con giardino [C]. Il castello dell'Acciaiolo a Scandicci:un complesso monumentale restaurato. Lavis (Trento): Alcion, 2010. 34-40.

[26] De Vita, Maurizio. Il castello dell'Acciaiolo a Scandicci:un complesso monumentale restaurato $[\mathrm{M}]$, Lavis (Trento): Alcion, 2010.

[27] Andrea Martellacci. Tracce di viaggio prima-durante il restauro [C]. Il castello dell'Acciaiolo a Scandicci:un complesso monumentale restaurato. Lavis (Trento): Alcion, 2010. 13-17.

[28] [28] Francesco Gurrieri. L'Acciaiolo, un moltiplicatore sociale e culturale fi nalmente "in servizio" [C]. Il castello dell'Acciaiolo a Scandicci:un complesso monumentale restaurato. Lavis (Trento): Alcion, 2010: 17-19.

[29] Xi Cheng. The Evolution of Architectural Heritage Protection Thought $[\mathrm{M}]$. Tongji University Press: Shanghai, 2016: 198-206.

[30] De Vita, Maurizio. Architetture nel tempo: dialoghi della materia, nel restauro [M]. Vol. 1. Firenze University Press, 2015.
[31] Girard. L. F, De Toro. P. Integrated spatial assessment: a multicriteria approach to sustainable development of cultural and environmental heritage in San Marco dei Cavoti, Italy [J]. Central European Journal Operational Research, 2007, 15 (3): 281-299.

[32] Xiaoming Zhu. ANALYSIS OF THE CULTURAL HERITAGE CONSERVATION SYSTEM ON THE LEVEL OF CENTRAL GOVERNMENT IN ITALY [J]. World Architecture, 2009 (06): 114-117.

[33] Gill Chitty.. Heritage, conservation and community: engagement, participation and capacity building [M]. Routledge: UK, 2016: 41-43.

[34] Guochao Zhang. Experience and Enlightenment of Italian Architectural Heritage [J]. Theory Monthly, 2020 (01): $110-118$.

[35] Ying Zhang, Youbo Zhuang, Rui Yang. Research on the typical model of community co management of nature reserves in the world [J]. Landscape Architecture, 2020, 27 (03): 18-23.

[36] S. Settis. Il patrimonio artistico tra scienza e politica: Europa e Italia [J]. Arte+Architettura in Svizzera, 2008, 1: 30.

[37] M. L. Buccolo. aring for heritage: public participation in the spotlight. [D]. Netherlands: Reinwardt Academy, 2016. 